\title{
Ordu ilinde findık (Corylus avellana L.) tarımı yapılan toprakların çinko (Zn) beslenme durumu ve potansiyel beslenme problemlerinin belirlenmesi
}

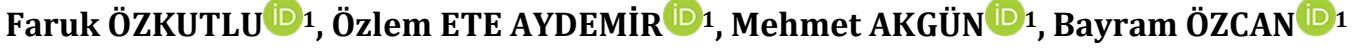

10rdu Üniversitesi, Ziraat Fakültesi, Toprak Bilimi ve Bitki Besleme Bölümü, ORDU

Alınış tarihi: 2 Temmuz 2019, Kabul tarihi: 1 Ekim 2019

Sorumlu yazar: Faruk ÖZKUTLU, e-posta: farukozkutlu@hotmail.com

\section{Öz}

$\mathrm{Bu}$ çalışmanın amacı Ordu ilinde findık tarımı yapılan bazı alanların topraklarda yarayışlı çinko (Zn) beslenmesi bakımından genel durumunu belirlemek ve ayrıca toprakların çeşitli fiziksel ve kimyasal özelliklerinin yarayışlı Zn element kapsamlarıyla ilişkilerini saptamaktır. $\mathrm{Bu}$ amaçla Ordu ili Ünye ilçe sınırından Gülyalı ilçe sınırının sonuna kadar olan bazı bahçelerden $0-30 \mathrm{~cm}$ derinlikten 130 adet toprak örneği alınmıştır. Alınan toprak örneklerinden DTPA yöntemiyle ekstrakte edilebilir $\mathrm{Zn}, \mathrm{Fe}, \mathrm{Mn}$ ve $\mathrm{Cu}$ belirlenmiștir. Mikro elementlerden toprakta yarayıșlı bor (B) analiziyle sonuçlarının açıklanmasında yardımcı olacak bazı fiziksel ve kimyasal analizler de yapılmıştır. Analiz sonuçlarında findık veriminin artmasında rolü olacak çarpıcı sonuçlar bulunmuştur. Fındık yetiştiriciliği yapılan bahçelerde büyük bir mineral beslenme problemi olduğu tespit edilmiștir. Özellikle findık yetiștiriciliğinin yoğun olarak yapıldığı bahçelerde genellikle asit bölge toprakları olduğundan Zn'nun yetersizliğinden ziyade Zn'nun fazlalığının olduğu sanılmaktadır. Ancak bu bilginin aksine Ordu ili findık bahçelerinin Zn ile beslenmesinin oldukça yetersiz olduğu belirlenmiştir. Analiz sonuçlarına göre, en düşük $\mathrm{Zn}$ konsantrasyonu $0.05 \mathrm{mg} \mathrm{kg}^{-1}$ iken en yüksek $\mathrm{Zn}$ konsantrasyonu $1.94 \mathrm{mg} \mathrm{kg}^{-1}$ olduğu belirlenmiş ve ortalama $0.45 \mathrm{mg} \mathrm{kg}^{-1}$ olarak saptanmıştır. Toprakta yarayışlı Zn kritik sınır değerleriyle karşılaştırıldığında toplam örneklerin \% 78'i 0.2-0.7 mg kg-1 arasında olup Zn bakımından "az" ve \% 11'i de < 0.2 sınır değerinde düşük, "çok az" olarak belirlenmiștir. $\mathrm{Bu}$ oranlarla findık yetiștiriciliğinin yoğun olarak yapıldığı bahçelerde \% 89 oranında Zn noksanlığı olduğu tespit edilmiştir. Doğu Karadeniz Bölgesi'nde Ordu ilinin diğer üretici illeri olan Samsun, Giresun ve Trabzon'a göre ve diğer üretici ülkelerden ABD, İspanya ve İtalya'ya kıyasla fındık veriminin düşük olmasının nedenleri arasında $\mathrm{Zn}$ ile beslenme sorunu verimliliği sınırlayan gizli bir etmen olabilir. Çinko (Zn) beslenmesinden başka, fındık verimini doğrudan ve dolaylı olarak etkileyen B (bor) bakımından da findık bitkisinin \% 85 oranında yetersiz beslendiği bulunmuştur.

Anahtar kelimeler: Findık, Zn, bor, verim

\section{Determination of potential nutritional problems and Zinc (Zn) status of hazelnut (Corylus avellana L.) grown soils in ordu province}

\begin{abstract}
The objective of this study was to determine the general status of hazelnut-grown soils in Ordu province in respect to available zinc ( $\mathrm{Zn}$ ) nutrition and the relationships of various physical and chemical soil characteristics with the content of available Zn. For this purpose, 130 soil samples from 0-30 depths were taken in some orchards located between the borders of Ünye and Gülyalı districts of Ordu. The contents of extractable $\mathrm{Zn}, \mathrm{Fe}, \mathrm{Mn}$, and $\mathrm{Cu}$ of the soil samples were determined using DTPA method. Available boron (B) in soil and certain physical and chemical analyses were also carried out. The results of the analyses revealed striking findings indicating a vital role in increasing hazelnut yield. It has been ascertained that there was a great nutritional problem in hazelnut orchards. Zn abundancy, rather than Zn deficiency, is considered a
\end{abstract}


problem in the region, since the hazelnut-grown soils are generally acidic. On the contrary, $\mathrm{Zn}$ nutritional status of hazelnut orchards in Ordu province was found to be very low. According to the results of the analysis, the lowest $\mathrm{Zn}$ concentration was $0.05 \mathrm{mg} \mathrm{kg}^{-1}$, whereas the highest was $1.94 \mathrm{mg}$ $\mathrm{kg}^{-1}$, with the mean $0.45 \mathrm{mg} \mathrm{kg}^{-1}$. When compared soil available $\mathrm{Zn}$ contents with the critical limit values, $78 \%$ of the total samples was classified as "low" (0.2-0.7 mg kg-1) and $11 \%$ was "very low" $\left(<0.2 \mathrm{mg} \mathrm{kg}^{-1}\right)$. Based on these figures, it was stated that $\mathrm{Zn}$ was deficient in $89 \%$ of hazelnut-grown soils in Ordu province. Among the reasons why hazelnut yield in Ordu province is lower than in other hazelnut producing provinces, such as Samsun, Giresun and Trabzon in the Black Sea region and other hazelnut producing countries such as the USA, Italy and Spain, Zn nutritional status of the soils may be a disguised yield limiting factor. Other than $\mathrm{Zn}$ nutrition, $85 \%$ of hazelnut-grown soils in Ordu was deficient in terms of $\mathrm{B}$ (boron) that affects yield directly and indirectly.

Key words: Hazelnut, zinc, boron, yield

\section{Giriş}

Türkiye'de findık (Corylus avellana L.) dikim alanı 2017 yılı verilerine göre 705.500 hektar olup bu alanın 227.121 hektar'lık kısmında Ordu ilinde findık tarımı gerçekleşmektedir (Anomin, 2017). Türkiye'de 2010-2017 yılları arasında hektar başına en düşük fındık verimi 2014 üretim yılında $590 \mathrm{~kg}$ iken en yüksek fındık verimi 2017 üretim sezonunda $960 \mathrm{~kg}$ olmuştur (TUIK, 2018). Ülkemizde hektar başına alınan bu verim değerleri diğer ülkelere kıyasla 2.5 kat daha düşüktür. Ülkemiz fındık üretiminin \% 27-30'unu üreten Ordu ilinde ise fındık verimindeki düşüşler daha çarpıcıdır. Ordu ilinde 2014 verilerine göre hektar başına findık verimi 370 kg findık iken 2017 yılında ise $940 \mathrm{~kg}$ findık elde edilmiştir (Anomin 2018). Ordu ilinin hem Doğu Karadeniz hem de batı Karadeniz'deki üretici illere göre fındık verimi en düşük seviyededir. Bunun nedenleri arasında Ordu ilinin arazi yapısının çoğunlukla engebeli, toprak derinliğinin sığ olması, taşlılık, kayalılık sorunun varlığı, toprakta asitlik, bazlık sorunu, toprakların kireç içeriklerinin düşük olması ve en önemlisi besin element noksanlıklarının fazla olmasıyla ilișkilidir. Ordu ili fındık yetiştiriciliğinin yoğun olduğu alanlarda üreticilerin tekdüze bir şekilde gübreleme yaptıkları bilinmektedir. Ordu ilinde gübre tüketimi belirten rapora göre genellikle fındık yetiştiriciliğinde azot (N) ağırlıklı gübreleme yapılmakta ve N'un dişında diğer besin içeriklerine sahip gübrelemede çok az yer verildiği bildirilmektedir. Örneğin, Ordu ilinde 2017 yllında \% 90.1 oranında N'lu, \% 4.31 fosforlu (P), \% 5.48 kompoze ve \% 0.11 oranı ile K'lu gübre kullanıldığı bildirilmiştir (Anonim, 2017). Bu oranlardan görüldüğü gibi tekdüze bir gübreleme yapılmakta ve fındık verimini ciddi oranda etkileyen özellikle mikro elementlerden Zn'lu gübrelerin hiç kullanılmadığı görülmektedir. Alloway, (1995) tarafından bildirildiğine göre dünya tarım topraklarının toplam Zn içeriği $10-300 \mathrm{mg} \mathrm{Zn} \mathrm{kg-1}$ aralığındadır. Dünyada tarım topraklarının \% 30'unda ve Türkiye'de \% 49,8'inde Zn eksikliğinin (DTPA-Zn<0.5 $\mathrm{mg} \mathrm{kg}^{-1}$ ) olduğu tespit edilmiştir (Sillanpaa, 1982; Eyüpoğlu ve ark., 1998).Türkiye'nin birçok bölgesinde çinko noksanlığının bir sorun olduğunu açıklamıştır (Eyüpoğlu ve ark., 1998). Çinko noksanlığının daha fazla kireçli topraklarda görüldüğü ve iller bazında da Van (\% 94.74), Burdur (\% 94.12), Tunceli (\% 92.71), Erzurum (\% 88.89) ve Uşak (\% 87.50) illerinde yaygın olarak Zn noksanlığının olduğu bildirilmiştir (Eyüpoğlu ve ark., 1998). Topraklarda Zn'nun yarayışlılığını birçok faktör etkilemektedir. Bunları; toprak tekstürü, topraktaki $\mathrm{P}$ miktarı, bölgedeki iklim koşulları ve toprak pH'sı olarak sıralamak mümkündür. Çinko noksanlığı toprak pH's 6.5 ile 8.0 arasinda olan topraklarda yaygın olarak görülmektedir. Genellikle kireçli topraklarda Zn noksanlığının görülmesinin yanı sıra, asit karakterli, yıkanmış kum ve kumlu tınlı topraklarda sıklıkla Zn noksanlığı görülmektedir. Ordu ilinin yıllık yağış miktarı 1042 mm olup Zn yağışla üst topraktan kolayca yıkanıp uzaklaşabilmektedir. Topraktaki fosfor (P) miktarı da Zn noksanlığının oluşmasında önemli bir etkendir. Genellikle fazla yapılan P'lu gübreleme sonucunda bitkilere $\mathrm{Zn}$ taşınımı engellenmektedir. Bitkide Zn'nun önemli fonksiyonlarının bulunması nedeniyle Zn noksanlığ gösteren bitkilerin metabolik fonksiyonlarında gerilemeler olmaktadır. Çinko'nun bitkideki önemli fonksiyonlarında dolayı bitkisel ürünün verimi doğrudan veya dolaylı olarak etkilemektedir. Bu araştırmayla Ordu ili topraklarının bitkiye yarayışlı Zn durumlarının belirlenmesi amaçlanmıştır. 


\section{Materyal ve Metot}

Toprak örneklerinin alınması ve analize hazırlanması

Ordu ili Ünye ilçe sınırının sonundan başlayarak Gülyalı ilçe sınırının sonuna kadar olan alandaki bahçelerden alınan toprak örnekleri çalışma alanını oluşturmuştur. Araştırma alanından 130 farklı nokta tespit edilmiştir (Şekil 1). Toprak örneklerinin alınma noktalarının koordinatları kayıt altına alınmıştır. Toprak örnekleri bahçeleri temsil edecek şekilde 0-30 cm derinlikten alınmıştır. Alınan topraklar kurutulduktan sonra $2 \mathrm{~mm}$ 'lik elekten geçirilerek analize hazır hale getirilmiștir.

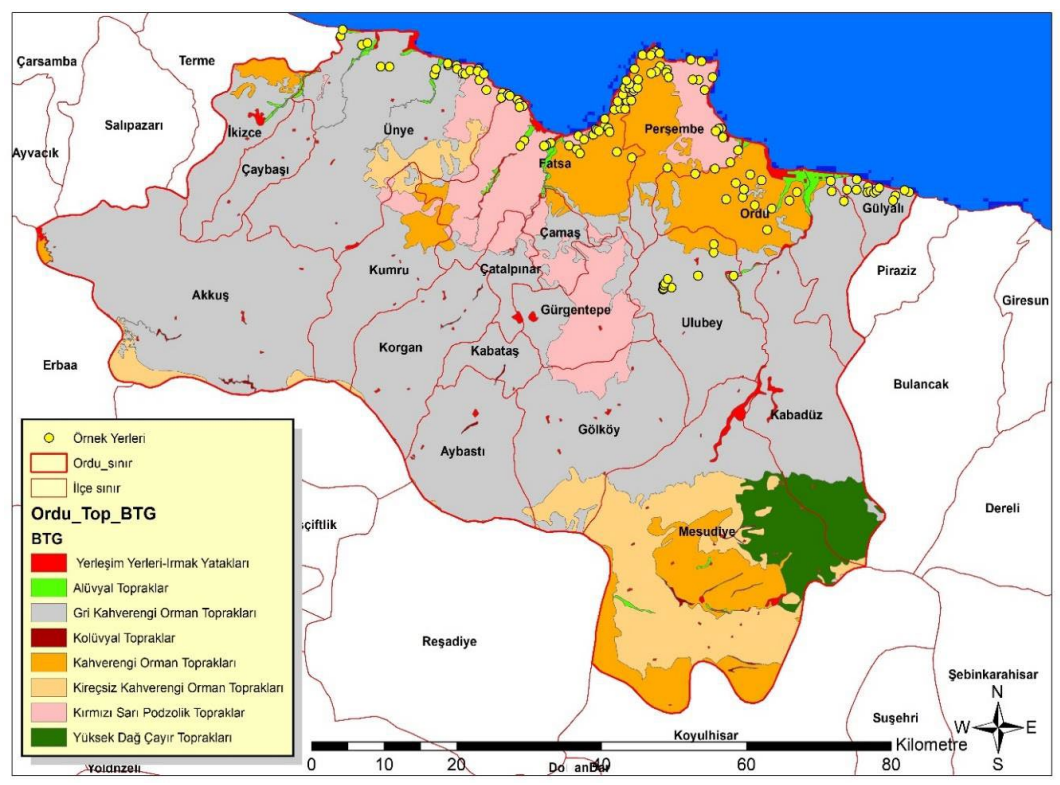

Şekil 1 Fındık bahçelerinden alınan toprak örneklerinin alınma noktaları

\section{Toprak analiz yöntemleri}

Gerekli analizler için hazırlanan toprak örneklerinde tekstür (Bouyoucos, 1951), pH (Jackson, 1959), EC ( $\mu \mathrm{s} \mathrm{cm}^{-1}$ ) (Richards, 1954), $\mathrm{CaCO}_{3}$ Scheibler kalsimetresiyle (Hızalan ve Ünal, 1966) ,ve organik madde Walkley- Black (Jakson, 1958) tarafından bildirildiği şekilde modifiye Walkley-Black yöntemine göre yapılmıştır.

Toplam N, (Bremner,1965) ile, alınabilir P, Bray ve Kurtz (1945), değișebilir $\mathrm{K}, \mathrm{Ca}$ ve $\mathrm{Mg}$ analizleri $1 \mathrm{~N}$ Amonyum Asetat ( $\mathrm{pH}=7)$ metoduna göre (Kacar, 1995) Alınabilir $\mathrm{Zn}, \mathrm{Fe}, \mathrm{Cu}$ ve $\mathrm{Mn}$ analizi Lindsay ve Norvell (1978)'e göre yapılmıştır. 0,005 M DTPA + $0,01 \mathrm{M} \mathrm{CaCl}_{2}+0,1 \mathrm{M}$ TEA, $\mathrm{pH}=7,3$ ile elde edilen çözeltiyle ekstrakte edilerek atomik absorpsiyon spektrofotometre cihazıyla belirlenmiștir. Alınabilir B, topraktan sicak su ekstraksiyonu (Berger ve Truog, 1939;) sonrası, azometin-H çözeltisi ile renklendirilerek $420 \mathrm{~nm}$ dalga boyunda spektrofotometrede okunan bor değerleri, önceden oluşturulan ve içindeki B miktarları kesin olarak bilinen standart seri yardımı ile hesaplanarak değerlendirilmiştir (Wolf, 1971).

\section{Bulgular ve Tartışma}

Toprakların tekstür (bünye), pH, tuz, kireç ve organik madde durumları

Araştırmada Ordu ili Ünye ilçesinin son sınırından başlayarak Gülyalı ilçesinin son sınırına kadar olan sahil şeridiyle Ordu merkez ilçenin findık yetiştiriciliğinin yoğun olduğu alanlardan toprak yapısının değişimleri dikkate alınarak bazı bahçelerden toprak örnekleri alınmıştır (Şekil 1). Bunların analizleri sonucunda toprakların tekstür (bünye) sınıflarında önemli farklılıkların olduğu belirlenmiştir. Bünye sinıfları killi topraktan tın sınıfına kadar farklılıkların olduğu saptanmıştır. Toplam toprak örneklerinin 38 tanesi \% 29 oranında kumlu tın özelliğe sahip olduğu belirlenmiştir (çizelge 1). Killi topraklarda bitkiye yarayışlı Zn kumlu topraklara göre daha fazla bulunmaktadır (Alloway, 2008; Taşdemir, 2006 ). Topraklarda kil miktarı artıkça Zn adsorbsiyonu artmaktadır (Marsener,1995). Bunun aksi durumunda topraklar kumlu olduğunda adsorbsiyon azaldığından yağışın bol olduğu alanlarda $\mathrm{Zn}^{+2}$ kolayca yıkanabilme özelliğine sahiptir. 
Toplam toprak örneklerinin pH'larının çok geniş bir aralıkta olduğu ve kuvvetli asit karakterden hafif alkali karaktere kadar değişen oranlarda bulunduğu saptanmıştır. Toplam toprak örneklerinin \% 40'ı hafif asit iken \% 2'si kuvvetli asit yapıda olduğu bulunmuştur. Genel olarak yağışın bol olduğu alanlarda toprakların çok kuvvetli asit karakterli olduğu düşünülmektedir. $\mathrm{Bu}$ nedenle de bazı durumlarda gereğinden fazla veya hiç ihtiyaç yok iken üreticiler kireçleme yaparak Zn eksikliğine yol açabilmektedir. Asit tepkimeli topraklarda kireçleme yapılması durumunda, çinkonun yarayışlılığının azalması tepkimeye girmemiş $\mathrm{CaCO}_{3}$ parçacıklarının yüzeyinde Zn'nun tutulmuş olması ile açıklanmaktadır (Tisdale ve ark.,1985).
Mikro elementler içersinde Zn'nun bitkilere olan yarayışlılığı toprak pH'sından oldukça etkilenmektedir. Toprak özellikleri arasında Zn'nun bitkilerce alınabilirliğini sınırlayan en önemli faktörün toprak pH'sı olduğu ifade edilmektedir (Marschner, 1993) . Toprak pH'sındaki bir birim artışa karşın Zn'nun yarayışlılığı 30-100 kat azalmaktadır. Çinko'nun çözünürlüğü pH'ya son derece bağlı olmakta ve $\mathrm{Zn}$ çözünürlügü ile $\mathrm{pH}$ değeri arasında negatif bir ilişkinin olduğu bilinmektedir. Asit bölge topraklarında $\mathrm{Zn}$ fazlaca çözünür durumda olduğunda yüksek yağış ile ortamdan kolayca uzaklaşabilmektedir.

Çizelge 1 Toprak örneklerinin tekstür (bünye), pH, EC, kireç ve organik madde değerleri

\begin{tabular}{|c|c|c|c|c|}
\hline & Sınır Değeri & Değerlendirme & $\begin{array}{c}\text { Toplam Örnek } \\
\text { Sayısı }\end{array}$ & \% Dağılımı \\
\hline \multirow{5}{*}{ Tekstür (Bünye) } & & Killi & 20 & 15 \\
\hline & & Killi Tın & 36 & 28 \\
\hline & & Kumlu Killi Tın & 31 & 24 \\
\hline & & Kumlu Tın & 38 & 29 \\
\hline & & Tin & 5 & 4 \\
\hline \multirow{5}{*}{$\mathrm{pH}$} & $<4.5$ & Kuvvetli Asit & 2 & 2 \\
\hline & $4.5-5.5$ & Orta Asit & 36 & 28 \\
\hline & $5.6-6.5$ & Hafif Asit & 52 & 40 \\
\hline & $6.6-7.5$ & Nötr & 25 & 19 \\
\hline & 7.6-8.5 & Hafif Alkali & 15 & 11 \\
\hline $\mathrm{EC}(\mathrm{dS} / \mathrm{m})$ & $0-4$ & Tuzsuz & 130 & 100 \\
\hline \multirow{5}{*}{ Kireç $\left(\% \mathrm{CaCO}_{3}\right)$} & $0-1$ & Az Kireçli & 118 & 92 \\
\hline & $1-5$ & Kireçli & 3 & 2 \\
\hline & $5-15$ & Orta Kireçli & 3 & 2 \\
\hline & $15-25$ & Fazla Kireçli & 3 & 2 \\
\hline & $>25$ & Çok Fazla Kireçli & 3 & 2 \\
\hline \multirow{5}{*}{ Organik madde (\%) } & $<1$ & Çok Az & 3 & 2 \\
\hline & $1-2$ & $\mathrm{Az}$ & 41 & 32 \\
\hline & $2-3$ & Orta & 46 & 35 \\
\hline & $3-4$ & İyi & 28 & 22 \\
\hline & $4<$ & Yüksek & 12 & 9 \\
\hline
\end{tabular}

Yapılan araștırmada toprakların tamamı tuz'suz olup \% 92'si de az kireçli olarak sinıflandırılmıştır. Toprakların organik madde oranları orta düzeyde değerlendirilmiştir. Genellikle toprakların fazla kireçli, pH’sının yüksek olması ve düşük organik madde içeriğinin olduğu alanlarda Zn eksikliği yaygın olarak görülebilmektedir (Marschner, 1995). Organik madde Zn'nun topraktaki hem çözünürlüğünü hem de difüzyonunu arttırmaktadır (Moraghan and Moscagni, 1991; Hamilton ve ark., 1993). Sürdürülebilir tarım için toprak özelliklerinin uygun olması ve uygun olmayan toprak koşullarının düzeltilmediği durumlarda optimum düzeyde üretim yapılması mümkün olmamaktadır. Özellikle mikro elementlerden eksikliği en fazla görülen element $\mathrm{Zn}$ olup bitkilerde noksanlığı durumunda üretim olumsuz etkilenmektedir. Bitkisel üretimin $\mathrm{Zn}$ 'ca yetersiz olarak yapılmasıyla bitkisel ürünlerin insanları beslenme kalitesinde de düşüşe neden olması kaçınılmaz olacaktır(Welch and Graham, 2004). 


\section{Toprak örneklerinin bitkiye yarayışlı Zn durumu}

Ordu bölgesine ait alınan 130 adet toprak numunesinin analiz sonuçlarına göre, topraklarda bitkiye yarayışlı Zn durumları belirlenmiş ve bahçelerin Zn konsantrasyonu arasında geniş bir varyasyonun olduğu bulunmuştur. Buna göre, toprakların bitkiye yarayışlı Zn konsantrasyonu en düşük 0,05 ve en yüksek olarak $1,94 \mathrm{mg} \mathrm{kg}^{-1}$ düzeyinde olduğu saptanmıştır. Topraklarda DTPA ile ekstrakte edilebilir Zn'nun değerlendirmesinde kritik sınır değer olarak <0.5'de küçük olanlar kullanılmaktadır(Lindsay ve Norvel, 1978). Ancak, XVIII International Plant Nutrition Colloquium with Boron and Manganese Satellite Meetings kongresinde Dünya'da tarım yapılan alanların \% 30'unda yaygın olarak $\mathrm{Zn}$ noksanlığ (Sillanpa, 1982 ) için kritik sınır değer olarak Zn konsantrasyonu $<0,7 \mathrm{mg} \mathrm{kg}^{-1}$ den düşük olan toprakların $\mathrm{Zn}^{\prime} \mathrm{ca}$ yetersiz toprak olarak değerlendirilmesinin uygun olacağı konusunda fikir birliği oluşmuştur. Bu çalışmada değerlendirilen toprakların Zn konsantrasyonları $<0,7$ değerine göre sınıflandırılmıștır. Ordu yöresinden alınan ve analizi yapılan toprak örneklerinin topraktaki $\mathrm{Zn}$ yeterlilik sınır değeriyle karşılaştırıldığında örneklerin toplam $\%$ 89'u $<0,7 \quad \mathrm{mg} \mathrm{kg}^{-1}$ 'den düşük olduğu, bu toprakların $\mathrm{Zn}$ bakımından yetersiz olarak değerlendirilmesine karşı örneklerin \% 11'nin ise toprak $\mathrm{Zn}$ konsantrasyonunun $0.7-2.4 \mathrm{mg} \mathrm{kg} \mathrm{kg}^{-1}$ arasında olduğu belirlenmiş ve $\mathrm{Zn}$ bakımından sinırlılık değerlerine göre bu toprakların yeterli olduğu saptanmıştır (Çizelge 1). Bu sonuçlardan görüldüğü gibi Ordu yöresinde yaygın bir $\mathrm{Zn}$ eksikliği söz konusudur. Türkiye de 14 milyon hektarlık alanda çinko eksikliğinin olduğu bildirilmiştir (White Zasoski, 1999; Alloway, 2004; Çakmak, 2008). Özellikle şiddetli Zn noksanlığının Orta ve Doğu Anadolu Bölgesinde yoğunlaştığı bildirilmiştir. Eyüpoğlu ve ark., (1994) yaptığı bir çalışmada Türkiye'nin değişik bölgelerini temsil edecek şekilde 1511 toprak örneği toplanarak analizleri yapılmıștır. DTPA-Zn analizleri sonucunda, tüm toprakların \% 49.8'inde Zn noksanlığının olduğu saptanmıștır. Bugüne kadar Karadeniz Bölgesi'nde $\mathrm{Zn}$ noksanlığından ziyade $\mathrm{Zn}$ fazlalığının olduğu sanılmaktaydı. Bu araştırma sayesinde Ordu ilinde yaygın bir $\mathrm{Zn}$ noksanlığının bulunduğu ortaya konulmuştur. Ordu yöresinde fındık veriminin düşük olmasının gizli nedenleri arasında Zn'nun önemli bir yer tuttuğu düşünülmektedir.

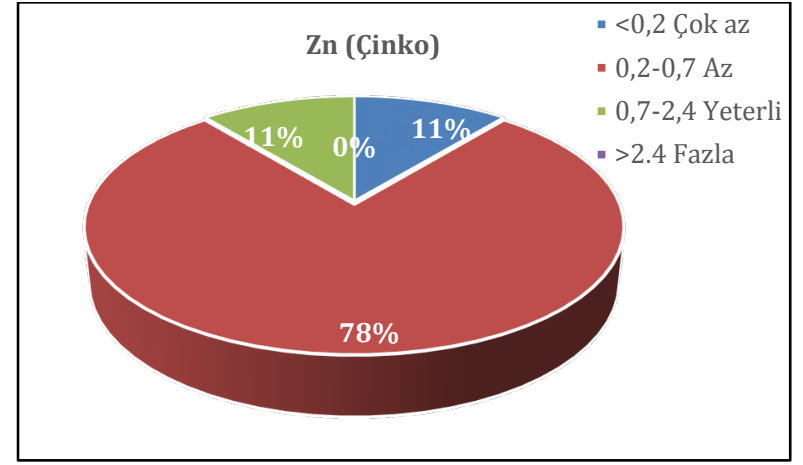

Şekil 2 Toprakta bitkiye yarayışlı Zn durumu ve dağılımı

Toprakların Demir (Fe), Bakır (Cu), Mangan (Mn) ve Bor (B) durumları ve $\mathrm{Zn}$ ile ilișkileri

Mikro elementler bitkiler için gerekli olup eksikliğinde bitkide o elemente özgü noksanlık belirtileri ortaya çıkmaktadır. Noksanlığı görülen elementin bitkide fizyolojik işlevlerine göre bitkisel verimde sinırlamalara neden olmaktadır. Findık yetiştiriciliğinin yoğun olduğu Ordu ilinde $\mathrm{Fe}, \mathrm{Cu}$ ve $\mathrm{Mn}$ durumlarının genellikle yeterli olduğu saptanmıştır. Ordu bölgesine ait toprakların Fe konsantrasyonları toprak sinır değeriyle karşılaştırıldığında toplam örneklerin \% $1^{\prime \prime} \mathrm{i} F$ bakımından yetersiz iken örneklerin \% 2'inde ise noksanlık görülebilir sınırında olup toplam örneklerin \% 97'si se Fe bakımdan yeterli olduğu bulunmuştur. Bitkilerin beslenmesinde demir $\mathrm{x}$ çinko (FexZn) interaksiyonu oldukça kompleks durumdadır. Çinko bakımından yetersiz bir toprağa Zn'lu gübreleme yapıldığında bitkinin $\mathrm{Fe}$ alımını arttığı açıklanmıştır (Jolley ve Brown, 1991 ). Ancak, bitkide fazla miktarda Fe olduğunda Zn'nun azaldığ da tespit edilmiştir (Norvell ve Welch 1993). Yarayışlı $\mathrm{Fe}$ ve Zn konsantrasyonları düşük olan topraklarda yapılan bir çok çalışmada, özellikle Zn'lu gübreleme sonucunda verimde kayda değer artışların meydana geldiği sağlamıştır (Çakmak ve ark., 1996). Bitkilerin yüksek oranda Fe beslenmesi sonucunda bitkiler tarafindan $\mathrm{Zn}$ alımını engellemekle birlikte bitkilerde $\mathrm{Zn}$ noksanlığının meydana gelmesine de neden olmaktadır (Alpaslan ve Taban, 1996). Çizelge 2 incelendiğinde Ordu topraklarının bitkiye yarayışlı $\mathrm{Cu}$ durumları \% 97 oranında yeterli olduğu bulunmuştur. Birçok bitkide $\mathrm{Cu} \times \mathrm{Zn}$ arasında bir interaksiyon yer almaktadır. Bu durum başlıca iki mekanizma ile meydana geldiğine inanılmaktadır. Bunlar: a) Bitki kökleri üzerindeki absorbsiyon yüzeyleri aynı olduğu için $\mathrm{Cu}$ ve $\mathrm{Zn}$ rakip olarak sürekli yarışmaktadırlar ve b) $\mathrm{Cu}$ bitki 
içinde Zn'nun gerekli yerlere taşınmasını engellemektedir (Kochian, 1993; Kacar, 2019). Yapılan araştırmada toplam örneklerin \% 2'sinin Mn bakımından yetersiz olduğu ve \% 98'ininde yeterli olduğu saptanmıştır (Çizelge 2).

$\mathrm{Bu}$ araştırmanın çarpıcı sonuçlarından birisi de fındık bahçelerinin topraklarında yüksek oranda B noksanlığının tespitine yöneliktir. Buna göre, toprakların \% 85'i B bakımından yetersiz iken \% 15'inin yeterli olduğu saptanmıştır (Çizelge 2, Şekil 2). Bor noksanlığında, bitkilerde meydana gelen bazı fizyolojik süreçlerin yavaşlaması veya bu süreçlerin tamamen durması söz konusu olmaktadır (CamachoCristóbal ve ark., 2011). Bor noksanlığı genel olarak ılıman iklime sahip ve bol yağıș olan bölgelerde görülmektedir. Ordu yöresinde yıllık yağış miktarının yüksek olmasıyla ilişkili olarak en fazla noksanlığı görülen mikro elementlerden $\mathrm{Zn}$ ve B olarak karşımıza çıkmaktadır. Son yıllarda dünya genelinde mikro besin elementleriyle ilgili olarak bitkisel üretimde en yaygın beslenme sorununun özellikle B ve Zn elementlerinden kaynaklandığı ileri sürülmektedir. Bitkilerin beslenmesinde $\mathrm{Zn}$ ve $\mathrm{B}$ arasında sinergistik etkileşim bulunmaktadır (Özkutlu ve ark., 2017). Özellikle kurak yörelerde topraklardaki Zn yetersizliği bitkilerdeki B toksisitesini artmasına neden olurken yağışlı bölgelerde de her iki elementin uzaklașmasına bağlı olarak bitkilerde ciddi verim kayıplarına neden olmaktadır.

Çizelge 2 Toprak örneklerinin Fe, Cu, Mn ve B konsantrasyonları

\begin{tabular}{|c|c|c|c|c|}
\hline Mikro Element & $\frac{\text { Sinır Değeri }}{(\mathrm{ppm})}$ & Değerlendirme & $\begin{array}{c}\text { Toplam Örnek } \\
\text { Sayısı }\end{array}$ & Dağılımı (\%) \\
\hline \multirow{3}{*}{$\mathrm{Fe}$} & $<2.5$ & $\mathrm{Az}$ & 1 & 1 \\
\hline & $2.5-4.5$ & $\begin{array}{l}\text { Noksanlık } \\
\text { görülebilir }\end{array}$ & 2 & 2 \\
\hline & $>4.5$ & İyi & 127 & 97 \\
\hline \multirow{3}{*}{$\mathrm{Cu}$} & $0.2-0.25$ & Orta & 2 & 1 \\
\hline & $0.25-1$ & Yeterli & 27 & 21 \\
\hline & $>1$ & Fazla & 101 & 78 \\
\hline \multirow{4}{*}{$\mathrm{Mn}$} & $<0.2$ & Çok az & 1 & 1 \\
\hline & $0.2-0.7$ & $\mathrm{Az}$ & 1 & 1 \\
\hline & $0.7-5.0$ & Yeterli & 17 & 13 \\
\hline & $>5.0$ & Fazla & 111 & 85 \\
\hline \multirow{4}{*}{$\mathrm{B}$} & $<0.5$ & $\mathrm{Az}$ & 111 & 85 \\
\hline & $0.5-2.0$ & Yeterli & 19 & 15 \\
\hline & $2.0-5.0$ & Fazla & - & \\
\hline & $>5.00$ & Çok fazla & - & \\
\hline
\end{tabular}

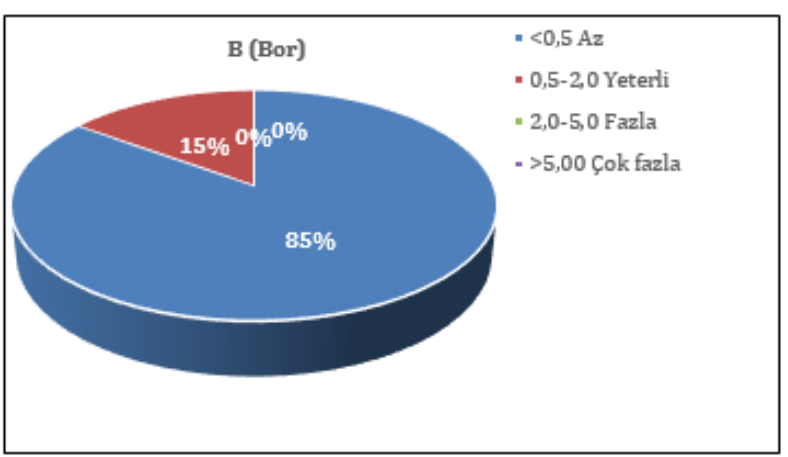

Şekil 3 Toprakların bitkiye yarayışlı b durumları ve dağılımları

Ordu yöresi topraklarının makro azot (N), fosfor (P), potasyum $(\mathrm{K})$, kalsiyum (Ca) ve magnezyum $(\mathrm{Mg}$ ) element sonuçlarının toprak sınır değerleriyle karşılaştırılarak dağılımları toplu olarak çizelge 3'te verilmiștir. Ordu iline ait toprakların $\mathrm{N}$ konsantrasyonları \% 5'nin az ve \% 43'nun orta düzeyde olduğu bulunmuştur. Son yıllarda yapılan çalışmalar bitkide Zn taşınımı ve bitkinin $\mathrm{N}$ beslenme düzeyi arasında önemli bir ilişkinin olabileceği ortaya konulmuştur. Yeterli N koşullarında Zn'nun bitkiye taşınmasının daha fazla olduğu açıklanmıştır (Öztürk ve ark., 2011). Azot'un bitki dokusunda bulunan $\mathrm{Zn}$ yoğunluğu üzerine olan olumlu etkisi, kök bölgesinden $\mathrm{Zn}$ alımını ve bitkinin üst aksamında gelişimi üzerine de önemli rol almasıyla açıklanabilir (Schwartz ve ark., 2003; Monsant ve ark., 2008). Barut, (2012) tarafindan yapraktan Zn uygulamasının bitkinin $\mathrm{N}$ konsantrasyonunu arttırdığı ve topraktan $\mathrm{N}$ uygulamasının da bitkinin Zn konsantrasyonunda artış sağladığı açıklanmıştır.

Fındık verimini etkileyen en önemli elementlerden fosfor (P) bakımından çarpıcı sonuçların olduğu belirlenmiştir. Yapılan araştırmada fındık 
bahçelerinin topraklarında bitkiye yarayışlı $P$ bakımından önemli varyasyonların olduğu saptanmıştır. Toprakların P konsantrasyonu en düşük $0.7 \mathrm{mg} \mathrm{kg}^{-1}$ olmasına karşın en yüksek 197 mg $\mathrm{kg}^{-1}$ olduğu bulunmuştur. Fosfor'un bu kadar geniş bir varyasyonda olması fındık verimini düşük olmasının nedenleri arasında yer almaktadır. Toprakların P konsantrasyonları Ülgen ve Yurtsever (1995)'in bildirdiği sınır değerlerle karşılaştırıldığında toprak örneklerinin yaklaşık \% 57'si P bakımından noksan \% 43'nün ise orta düzeyden bașlayıp fazla sınıfına kadar olduğu tespit edilmiștir. Tarımsal olarak üretilen ürünün kaliteli ve veriminin yüksek olması bitki besin elementlerinin toprakta bulunan miktarlarına bağlı olduğu kadar, elementlerin kendi aralarında dengeli olması da bir o kadar önem taşımaktadır. Bitkilerin gelişimini sağlıklı olarak tamamlayabilmeleri için, gerekli olan besin elementlerinin bitkide bulunuş miktarı kadar, besin elementlerinin birbirleriyle olan iliş̧isi ve oranı da oldukça önem taşımaktadır. Yapılan araştırmada toprakların P konsantrasyonunun çok geniş bir varyasyon göstermesinin yanı sıra yüksek oran $\mathrm{Zn}$ noksanlığının olması dikkatleri P-Zn etkileşimine yöneltmektedir. Fosfor $\mathrm{x}$ çinko interaksiyonunda uygulanan fosfor dozları artıkça bitkinin çinko beslenmesi olumsuz etkilenmektedir. Fosfor'lu gübre uygulaması sonunda bitkiler tarafından Zn alımının azaldığı ya da Zn noksanlığının belirgin bir şekilde arttığını tespit etmiștir (Floneragan ve Webb,1993).

Çizelge 3 Toprak örneklerinin N, P, K, Ca ve Mg konsantrasyonları

\begin{tabular}{|c|c|c|c|c|}
\hline Makro Element & $\begin{array}{l}\text { Sinır Değeri } \\
\text { ppm }\end{array}$ & Değerlendirme & $\begin{array}{c}\text { Toplam } \\
\text { Örnek Sayısı }\end{array}$ & $\begin{array}{c}\text { Dağılımı } \\
\%\end{array}$ \\
\hline \multirow{5}{*}{$\mathrm{N}$} & $<0.05$ & Çok az & 2 & 2 \\
\hline & $0.05-0.07$ & $\mathrm{Az}$ & 4 & 3 \\
\hline & $0.07-0.15$ & Orta & 56 & 43 \\
\hline & $0.15-0.25$ & Fazla & 51 & 39 \\
\hline & $>0.25$ & Çok Fazla & 17 & 13 \\
\hline \multirow{5}{*}{$\mathrm{P}$} & $0-5$ & Çok az & 38 & 29 \\
\hline & 5-10 & $\mathrm{Az}$ & 37 & 28 \\
\hline & $10-15$ & Orta & 8 & 7 \\
\hline & $15-20$ & Yüksek & 9 & 7 \\
\hline & $>20$ & Çok Yüksek & 38 & 29 \\
\hline \multirow{4}{*}{$\mathrm{K}$} & $<50$ & Çok az & 6 & 5 \\
\hline & $50-100$ & $\mathrm{Az}$ & 29 & 22 \\
\hline & $100-300$ & Yeterli & 83 & 64 \\
\hline & $300-1000$ & Fazla & 12 & 9 \\
\hline \multirow{4}{*}{$\mathrm{Ca}$} & $<380$ & Çok az & 5 & 4 \\
\hline & $380-1150$ & $\mathrm{Az}$ & 12 & 9 \\
\hline & $1150-3500$ & Yeterli & 45 & 35 \\
\hline & $3500-10000$ & Fazla & 68 & 52 \\
\hline \multirow{5}{*}{$\mathrm{Mg}$} & $<50$ & & & \\
\hline & $50-160$ & $\mathrm{Az}$ & 6 & 5 \\
\hline & $160-480$ & Yeterli & 44 & 34 \\
\hline & $480-1500$ & Fazla & 76 & 58 \\
\hline & $>1500$ & Çok fazla & 4 & 3 \\
\hline
\end{tabular}

Ordu gübre tüketim alışkanlıklarında potasyum'lu ve magnezyum'lu gübrelerin neredeyse hiç kullanmadığı bilinmektedir. Fındık veriminde daha etkin olan çok besinli kompoze gübrelerin kullanılması daha yararlı olacaktır. Yapılan araştırmada fındık bahçelerinin $\mathrm{K}$ konsantrasyonlarında önemli farklılıkların olduğu ve en düşük K konsantrasyonu $39 \mathrm{mg} \mathrm{kg}^{-1}$ iken en yüksek K konsantrasyonu 422 mg kg-1 olarak bulunduğu saptanmıștır. $\mathrm{Bu}$ değerler kritik konsantrasyon değerleriyle klyaslandığında toprakların \% 27'sinin K konsantrasyonu "az" olarak bulunurken, \% 64'ünün yeterli olduğu tespit edilmiştir. En düşük Mg konsantrasyonu $66 \mathrm{mg} \mathrm{kg}^{-1}$ iken en yüksek Mg konsantrasyonu $2025 \mathrm{mg} \mathrm{kg}^{-1}$ olup ortalama $695 \mathrm{mg} \mathrm{kg}^{-1}$ olarak bulunmuştur. 


\section{Sonuçlar ve Öneriler}

Ordu yöresi findık bahçelerinde yüksek oranda beslenme sorunu olduğu saptanmıştır. Bu nedenle bahçelerin mutlak süretle toprak ve bitki analizlerine göre gübrelenmesi gerekmektedir.

Ordu yöresinde dekar başına alınan findık verimleri diğer illere göre düşük olmasının sebepleri arasında yüksek oranda makro ve mikro elementlerin eksikliklerinin olması gösterilebilir.

$\mathrm{Bu}$ araştırmanın en çarpıcı sonucu fındık bahçelerinde makro elementlerden başka toprakların yüksek oranda $\mathrm{Zn}$ noksanlığı olduğu tespitine yöneliktir.

Ordu ili fındık üreticilerinin gübreleme alışkanlığını değiştirmesi gerekmektedir. Çinko noksanlığı olan bahçelerde yörede bugüne kadar kullanılmayan Zn'lu gübrelemeye yer vermesi önerilmektedir.

Çinko'lu gübrelerin uygulanma metotları olarak iki yol izlenmelidir.

Sabah ve akşam saatlerinde güneşin olmadığı zamanlarda yapraktan sprey şeklinde,

Topraktan uygulamada ise işgücü masrafını azaltmak için kompoze gübre olarak serpme veya banda uygulama șeklinde verilebilir.

Yaygın kanıya göre Zn'lu gübrelemede topraktan uygulamanın yapraktan uygulama sonuçlarına klyasla daha iyi sonuç verdiği ileri sürülmektedir. Yapraklardaki eksiklik belirtileri şiddetli ise acil olarak yapraktan uygulamaların hızlı bir şekilde noksanlığı tedavi edebileceği dikkate alınmalıdır.

Çalışmada elde edilen bir başka önemli sonuçta fındık yetiştiriciliği yapılan alanlarda topraklarda yüksek oranda B noksanlı̆̆ının da olduğu saptanmıștır. $\mathrm{Bu}$ nedenle Ordu yöresinde topraklarında mevcut durumda olan analizlere göre mikro elementlerin de dahil edilmesi uygun olacaktır.

Karadeniz bölgesinde özellikle mikro elementler üzerine daha fazla çalışmalar yapılarak tarım ürünleri için verim ve kalite üzerine olan etkileri vurgulanmalıdır.

\section{Teşekkür}

$\mathrm{Bu}$ araştırma Karadeniz İhracatçı Birlikleri (KIB) tarafından desteklenmiştir. $\mathrm{Bu}$ araştırma desteklenen projeden üretilen doktora çalışmasının bir bölümünü oluşturmaktadır.

\section{Kaynaklar}

Alloway, B. J., 1995. Heavy metals in soils, 2nd edn. London, UK: Blackie Academic and Professional.

Alloway, B.J., 2004. Zinc in soils and crop nutrition. International Zinc Association Communications. IZA Publications, Brussels.

Alloway, B.J., 2008. Zinc in soils and crop nutrition. IZA Publications, İnternational Zinc Assoc.: Brussels.

Alpaslan, M., Taban, S., 1996. Çeltik (Oryza sativa L.)'te çinkodemir iliflkisi, Tar`m Bilimleri Dergisi, 2(1).

Anonim, 2017. TÜİK, İstatistiklerle Türkiye, 2017. Türkiye İstatistik Kurumu, Ankara.

Anonim, 2018. TÜIK, İstatistiklerle Türkiye, 2018. Türkiye İstatistik Kurumu, Ankara.

Barut, H., 2012. Farklı Doz Ve Zamanlarda Uygulanan Çinko Ve Azotun Buğdayda Tane Çinko Konsantrasyonu Üzerine Etkisi. Doktora tezi, Çukurova Üniversitesi Fen Bilimleri Enstitüsü.

Berger, K.C., Troug, E. 1945. Boron availability in relation to soil reaction and organic matter content. Soil Sci. Soc. Am. Proc. 10: 113-116.

Bremner, J.M., 1965. Total Nitrojen. In. C.A. Black et al. Methods of Soil Analysis. Part 2. Agronomy. 9: 1149-1178.

Bouyoucus, G.J., 1952. Arecalibration of hidrometer for making mechanical analysis of soils. Agron. J. 43: 434-438.

Bray, R. H., Kurtz, L. T., 1945. Determination of total, organic, and available forms of phosphorus in soils. Soil science, 59(1): 39-46.

Camacho-Cristobal, J. J., Rexach, J., Herrera-Rodriguez. M. B., Navarro-Gochicoa, M. T., Gonzak-les-Fontes, A. 2011. Boron deficiency and transcript level changes. Plant Science, 181: 85-89.

Çakmak, İ., 2008. Enrichment of cereal grains with zinc: Agronomic or genetic biofortification? Plant and Soil, 302: 1-17.

Çakmak, İ., Yılmaz, A., Kalaycı, M., Ekiz, H., Torun, B., Erenoğlu, B., Braun, H.J., 1996. Zinc deficiency as a critical problem in wheat production in central anatolia. plant and soil. 180: 165-172. Phytologist, 146: 185-205. 
Eyüpoğlu, F., Kurucu, N., Sanisa, U., 1994. Status of plant available micronutrients in Turkish soils (in Turkish). Annual Report, Report No: R-118. Soil and Fertilizer Research Institute, Ankara, 1994: 2532.

Eyüpoğlu, F., Kurucu, N., Talaz, S., 1998. Türkiye Topraklarının Bitkiye Yarayışlı Çinko Bakımından Genel Durumu. I. Ulusal Çinko Kongresi, 99-106, Eskişehir.

Floneragan, J... Webb, M. J., 1993. İnteraction between zinc and other Nutrients affecting the growth of plants. P. 119-134. In: Zinc in Soils and Plants. Edited by A.D. Robson. Springer-Science +Bussiness Media, B.V.

Hızalan, E., Ünal, H., 1966. Topraklarda önemli kimyasal analizler. AÜ Ziraat Fakültesi Yayınları, 278.

Jackson, M. L,. 1958. Soil chemical analysis. Prentice Hall, Englewood Cliffs, New Jersey, USA.

Jackson, M.L., 1959. Soil chemical analysis. Englewood Cliffs, New Jersey.

Jolley, V. D.,. Brown, J. C., 1991. Factors in iron-stress response mechanism enhanced by Zn-deficiency stress in Sanilac, but not Saginaw navy beans. J. Plant Nutr. 14: 257-265.

Kacar, B., 1995. Toprak analizleri (bitki ve toprağın kimyasal analizleri III). Ankara Üni., Zir. Fak., Eğitim Araș. ve Geliștirme Vakfı Yayınları, 81-86.

Kacar, B., 2019. Sürdürülebilir Tarımda Mikro Besin Maddeleri. Ankara Üniversitesi Ziraat Fakültesi Yayınları No: 2216, 712s

Kochian, L. V. 1993. Zinc absorption from hydroponic solution by plant roots. Chap 4 in Robson, A.D. (ed) Zinc in Soils and Plants, Kluwer Academic Publishers, Dordrecht. pp 45-58.

Lindsay, W. L., Norvell, W. A., 1978. Development of a DTPA soil test for zinc, iron, manganese and copper. Soil Science Society of America Journal 42, 421- 428.

Marschner, H,. 1993. Zinc uptake from soils. Chap 5 in Robson, A.D. (ed.) Zinc in soil and plants. Kluwer Academic Publishers, Dordrecht, pp 48-78.

Marschner, H., 1995. Mineral nutrition of higher plants. Second Edition. Academic Press, NewYork, USA.
Monsant, A. C., Tang, C., Baker, A. J. M., 2008. The effect of nitrogen form on rhizosphere soil $\mathrm{pH}$ and zinc phytoextraction by Thlaspi caerulescens. Chemosphere 73(5): 635-642.

Moraghan, J. T., Mascogni, J.R., 1991. Enviromental and soil factors affecting micronutrient deficiences and toxities. Madison, W.I. SSSA Book Series, No:4, pp. $371-425$

Norvell, W. A., Welch, R. M., 1993. Growth and Nutrient uptake by barley (Hordeum vulgare L. cv Herta) Studies using an N-(2Hydroxyethyl)ethylenedinitrilotriacetic acid buffered nutrient solution technique. I. Zinc ion requiremenets. Plant Physiol. 101: 619-625.

Özkutlu, F., Korkmaz, K., Şahin, Ö., Akgün, M., Ete, Ö., Tașkın, B., \& Aygün, A., 2017. Ordu ve Samsun yörelerindeki fındık bahçelerinin bor beslenme durumunun belirlenmesi. Akademik Ziraat Dergisi, 6(1): 53-62.

Öztürk, L., Erenoğlu, B., Kaya, Y., Altıntaş, Z., Haklı, E., Andi, E., Yılmaz, Ö., 2011. Çinko'nun Buğday Tanesine Tasınmasını Etkileyen Fizyolojik Mekanizmaların Arastırılması, Tübitak Projesi Sonuç Raporu, Proje No: $108 \mathrm{~T} 436$.

Richards, L. A., 1954. Diagnosis and improvement of saline and alkali Soils. United States Depatyment of Agriculture Handbook, 60.

Schwartz, C., Echevarria, G., Morel, J. L., 2003. Phytoextraction of cadmium with Thlaspi caerulescens. Plant and Soil 249, 27-35.

Sillanpaa, M., 1982. Micronutrient and the nutrient status of soils. A Global Study FAO Soils Bulletin, No:48., FAO, Rome, Italy.

Taşdemir, 2006. Değişik Azot ve Çinko Dozlarının Buğday Bitkisinde Büyüme ve Verim Üzerine Etkisi. Çukurova Üniversitesi Fen Bilimleri Toprak Anabilim Dalı, Doktora Tezi, Adana, 78s.

Tistale, S. M., Nelson, W. L., Beaton, J. D., 1985. Soil fertility and fertilizers. 4 th Ed. P. 1-754, Mac Millan Publishing Company, New York.

Ülgen, A.N., Yurtsever, N. (1995). Türkiye gübre ve gübreleme rehberi. Tarım Orman ve Köyişleri Bakanlığı Toprak ve Gübre Araștırma Enstitüsü Müdürlüğü. 
Welch, R. M., Graham, R. D., 2004. Breeding for micronutrients in staple food crops from a human nutrition perspective. Journal of Experimental Bot 55: 353-364.

White, J. G., Zasoski, R. J., 1999. Haritalama soil micronutrients. Field Crops Res. 60: 11-26.
Wolf, B., 1971. The determination of boron in soil extracts, plant materials, composts, manures, water and nutrient solutions. Communications in Soil Science and Plant Analysis, 2(5): 363-374. 